\title{
Analysis of English Reading Mode Based on Reading and Writing
}

\author{
Jie Weng \\ Xi'an Peihua University, Xi'an, Shaanxi, 710125
}

Keywords: English reading mode; reading and writing; method study

\begin{abstract}
Reading and writing have their common cognitive mechanisms and language processing mechanisms. They are two aspects of reciprocity. Foreign input and input hypotheses, transfer theory, the concept of the teaching of the whole language and the theory of free reading provide theoretical support for reading and writing. Reading and writing correspond to input and output, respectively, and only when reading and writing is taught as a whole can language automation be achieved. The Chinese language teaching in middle schools in China has long proposed the combination of reading and writing. It is believed that reading and writing are complementary and inseparable. Reading and writing should be integrated and taught. This revelation also applies to English teaching, and more and more scholars have begun to study the integration of integrated language skills, read-write integration, reading and writing, and writing to promote reading.
\end{abstract}

\section{Introduction}

In the high school English teaching, reading teaching is a very important teaching content. In today's reading teaching, most of them do not pay enough attention to the cultivation of students' reading and writing skills, and they rarely combine the two for training. As a result, students did not realize the close connection between "listening, speaking, reading and writing" and the internal relationship between them. "Speaking, listening, reading, etc." The skills are in an independent state. The overall reading teaching effect is not satisfactory. To this end, it is necessary to actively analyze the current state of related teaching, understand the existing problems, and actively seek effective solutions to improve the teaching of English reading.

\section{Status of English Literacy in High School}

In high school English teaching, "reading" and "writing" are two very important teaching contents. However, traditional English teaching and examination has always focused on students' grammar and reading ability, etc. There is less attention to the combination of writing and reading, resulting in the separation of "reading" and "writing". The problem of a high degree of separation between "reading" and "writing" is not conducive to the improvement of students' comprehensive ability. Traditional high school English reading teaching has certain problems in terms of methods and methods. To this end, it is necessary to construct a new type of teaching model in a positive manner, and to combine "reading" and "writing" organically so as to achieve a double improvement in students' comprehensive ability and teaching level. In summary, there are two aspects of skills: First, shallow understanding of skills, namely the selection and use of vocabulary, grammar, and sentence patterns in the text; Second, deep understanding of skills, including paragraph convergence, layout, content selection , the overall ideological expression and the critical and creative thinking of the article. However, although teachers pay attention to reading teaching, the focus of teaching has deviated from the point of view of teaching in shallow understanding. Reading teaching has become vocabulary teaching and grammar teaching, resulting in the lack of reading skills and reading strategy teaching in reading teaching. Due to the lack of classroom experience, it is impossible to systematically master reading skills and strategies. As a result, reading teaching efficiency is low, and students' performance is difficult to improve.

In addition, the teaching mode is single and stylized. Teachers should ignore different genres and use different teaching methods for different reading purposes. Classroom teaching is 
teacher-centered, and the presupposition is too much. Intensive reading is confusing. In the classroom, students really read very little time, resulting in the failure of the student's subjectivity, lack of a real reading experience, and little experience in reading. reward. Students cannot obtain the self-efficacy of reading, nor can they experience the pleasure of reading. Naturally, they do not like to read and read less. In many studies of high school students' reading surveys, it is not difficult to find that the readings of high school students are far below the 10,000 words required by the seven-grade curriculum. Most students do not have the habit of reading outside class. This will inevitably result in insufficient reading and affect their reading performance, which is not conducive to the development of lifelong reading ability. Reading is the process by which people actively and constructively construct meaning. It is the process of development of people's thinking. Reading can give students a lot of language input. This type of input includes language knowledge, including the process of linguistic thinking: on the one hand, the author understands how the author designs, extracts content, and presents ideas. On the other hand, he integrates his own background knowledge, reconstructs articles, and interprets and trains himself. Students' critical and creative thinking. Just as "a thousand Hamlets in the eyes of a thousand readers," this is precisely the purpose that deep reading must achieve. The neglect of the reading thinking process in high school English reading teaching will inevitably lead to the one-sided and fragmented input of students' language, the lack of necessary experience in thinking in English, the cultivation of reading ability and the segmentation of other abilities, which will ultimately be detrimental to their comprehensive language ability.

\section{Problems in English Writing Teaching}

Teachers' insufficient attention to writing in classroom teaching leads to the lack of writing classes and the lack of student writing. Many teachers do not have guidance in the classroom writing process because of the tight class hours and limitations of their abilities. According to the survey, teachers' teaching of writing presents the process of "Classification of Writing in the Classroom and Writing of a Class of Students Marking After Class Writing”. The only instruction the student receives is the assignment of the teacher. There are only a few comments on the writing in the class. In most cases, students are required to refer to the sample text after class. Teachers misunderstood the meaning of the writing process and flowed to the final evaluation. Like reading, writing is a kind of cognitive activity. It is a process of discovering meaning and non-linear thinking. (Liu Yu, writing involves the use of language, the selection of content, the construction of chapters, the reproduction of meaning, etc. It is a positive and complex The process of thinking transformation is also an important process of training students to think in English. Writing requires substantive knowledge, but also requires the formation of sexual knowledge. Teachers often neglect the instruction of the writing process and ignore the impartation of formative knowledge, leading to the lack of students. With the necessary writing skills and strategies, there are many difficulties in writing and, in addition, there is a deviation in writing evaluation, and as in reading teaching, there is a bias toward vocabulary and grammar in writing teaching, and teachers ignore the holistic construction of texts and focus only on details. The linguistic points on the language are often replaced by vocabulary and grammar in the teaching of writing, and the teaching objectives are biased and cannot really play its role in thinking training. It can be said that, like reading teaching, writing teaching cannot achieve the purpose of skill training, and teaching effectiveness is not Significantly, student achievement is very slow. Students are less interested in writing and are tired and afraid of writing. Furthermore, teachers do not attach importance to the connection between writing and other language skills. Writing is the output of skills, there is a large amount of input will be output."Ordinary Senior High School English Curriculum Standards" ((Experiment) also explicitly requires students to develop their comprehensive language proficiency. However, due to the lag in teachers' teaching concepts and methods, the training of integrated language use ability is lacking. The neglect of the writing process guide results in few teachers being able to read input. At the same time, the students are instructed to pay attention to their help to the writing output. The input and the output are separated and the reading and writing are separated. The students can not 
understand the connection between the two thinking, the separation of thinking makes the reading blind, the student writing is a blank, both The vicious circle between the two will inevitably lead to less effective teaching and will not be conducive to the teaching of reading and the teaching of writing.

\section{The Specific Application of English Reading Teaching Mode Based on Reading and Writing Mode}

In the application process, different methods can be used, including rewriting and copying, as well as writing. In the process of rewriting after reading, students must first read the text in the teacher's guide. Through systematic, in-depth text reading, grasp the basic content of the text and language style. Afterwards, we rethought the reading activities, and then combined some of our previous learning experiences and skills with certain rewrites to improve our understanding of the text. In the specific rewriting process, different methods can also be used. In addition, it can also guide students to abbreviate training. Through certain abbreviations training, students can improve their text analysis ability and generalization ability, and help students better grasp the outline of the article. Then proceed with accurate refinement of the entire text to arrive at the meaning of the article and reproduce the content of the article.

In addition to copywriting and rewriting, students can also be instructed to write after reading. In the post-reading writing stage, the choice is to complete the teaching by guiding students to read subsequent writing and free writing. First, guide students to read and write. Through continuous writing, guide students to diverge thinking and write according to the previous text. In order to further train students' ability to use language and ability to arrange paragraphs, as well as maintain coherence and consistency in the context. In the process of writing, teachers can guide students in the process of extending the writing of the next step on the basis of grasping the structure and content of the original text as well as the emotional tone and language style. In the process of writing, students are encouraged to develop divergent thinking and develop their imagination. In accordance with their own understanding, they are constantly enriching their original textual content. In the renewal phase, students use the original text as a reference. Under certain restrictions, students write according to certain conditions. The difficulty of writing is relatively small. After completing the renewal, you can further increase the difficulty and guide students to write freely. In the free writing stage, students can no longer be constrained and restricted by previous texts, and they can freely use their own understanding and thoughts as well as their writing skills. Through their own different understandings, they publish different viewpoints, use different languages, and write skills. In writing, students can describe their own ideas and opinions with a high degree of freedom. However, it may also face some difficulties in language expression. Teachers can help and guide them in a timely manner and guide them to use the various secondary expressions they have learned to write. Through this stage of practice, students can make full use of various language knowledge and skills that they have previously learned and mastered to achieve knowledge output.

\section{Conclusion}

In the long-term high school education, the current situation of high school English literacy teaching was analyzed, and the status and problems of teaching were known. And based on the reading and writing mode, built an English reading teaching mode. Through practical application, it is further understood that English reading teaching in the reading and writing mode can achieve ideal results. Through practical application, it has also been found that the reading and writing mode of English reading teaching, compared with the experiment, the overall reading and writing levels of students have been greatly improved.

\section{References}

[1] He Wuhua. Reflections on the Teaching of Information Networking in Primary and Secondary 
School English [J]. Electro-Education Research, 2002(10).

[2] Sun Yuanyuan, Jiang Xiaoming, Yu Shengquan. Based on Handheld Devices, the Sino-England Teaching Model [J]. Modern Educational Technology, 2009(3).

[3] Wu Aiping, Song Tianming. Application of "master-host" teaching model in teaching of information technology [J]. China Electrification Education, 2009(8).

[4] Zhang Shulan. Analyze the application of intelligent speech systems in English teaching from a quantitative perspective [J]. Modern Educational Technology, 2012(5).

[5] Yu Xizhen. The Teacher Teaching Model Constructed by the Teacher's Guide and the Student's Subject [J]. Education Exploration, 2007(9). 